\title{
Distribusi dan Preferensi Habitat Udang Air Tawar Caridina ensifera Schenkel, 1902 pada Dua Inlet Danau Poso, Sulawesi Tengah
}

\section{(Distribution and Habitat Preference of Freshwater Shrimps Caridina ensifera Schenkel, 1902 in the Two Inlet Streams of Lake Poso, Central Sulawesi)}

\author{
Ni Luh Setiawati ${ }^{1 *}$ dan A. Annawaty ${ }^{1}$ \\ ${ }^{1}$ Lab. Biosistematika Hewan dan Evolusi, Jurusan Biologi, Fakultas MIPA Universitas Tadulako Jl. Soekarno Hatta \\ km 9 Tondo, Palu 94118, Sulawesi Tengah, Indonesia.
}

Keywords: Caridina ensifera, Streams, Lake Poso, Central Sulawesi.

Keywords: Caridina ensifera, Sungai, Danau Poso, Sulawesi Tengah.

${ }^{*}$ Coresponding Author : setiawatitya66@gmail.com

\begin{abstract}
The distribution and habitat preference of freshwater shrimps Caridina ensifera Schenkel, 1902 on two inlets of Lake Poso, Central Sulawesi have been studied. Freshwater shrimps samples was collected in two streams, namely the Pomua Palandu Stream and Toinasa Stream. The sampling station on each streams is divided into three locations based on the distance of the stream flow from its mouth at Lake Poso. Sampling is done by purposive sampling method using the tray net tool. The obtained samples were preserved using $96 \%$ alcohol and than identification was carried out at the Laboratory of Animal Biosystematic and evolution, Department of Biology, Tadulako University. The results showed that Caridina ensifera was only distributed in the lower reaches of the Pomua Palandu Stream and Toinasa Stream, having habitat preferences between plant roots that dangled into the water with rocky sand and sand substrates and very slow current speeds. According to von Rintelen and Cai (2009) Caridina ensifera is distributed in Lake Poso.
\end{abstract}

\begin{abstract}
Abstrak
Penelitian ini bertujuan untuk mengetahui distribusi dan preferensi habitat udang air tawar Caridina ensifera Schenkel, 1902 pada dua inlet Danau Poso, Sulawesi Tengah. Penentuan stasiun dibagi berdasarkan sungai yaitu Sungai Pomua Palandu dan Sungai Toinasa. Stasiun sampling pada masing-masing sungai dibagi menjadi tiga lokasi berdasarkan pada jarak aliran sungai dari muaranya di Danau Poso. Pengambilan sampel dilakukan dengan metode purposive sampling menggunakan alat tray net. Sampel yang diperoleh diawetkan menggunakan alkohol 96\%, kemudian diidentifikasi di Laboratorium Biosistematika Hewan dan Evolusi, Jurusan Biologi, Universitas Tadulako. Hasil penelitian menunjukan bahwa Caridina ensifera hanya terdistribusi di bagian hilir Sungai Pomua Palandu maupun Sungai Toinasa, memiliki preferensi habitat di sela akar tumbuhan yang menjuntai ke air dengan substrat pasir atau pasir berbatu serta kecepatan arus yang sangat lambat. Menurut von Rintelen and Cai (2009) Caridina ensifera terdistribusi di Danau Poso.
\end{abstract}

\section{Latar Belakang}

Udang air tawar merupakan anggota dari infraordo Caridea yang dapat menghuni habitat perairan tawar seperti kolam, danau, rawa dan sungai (Wowor et al., 2009). Udang air tawar ditemukan pada berbagai habitat yang berbeda di perairan yaitu di bawah serasah dedaunan, pada kayu yang telah lapuk, di bawah akar tanaman air atau di sekitar rerumputan dan di sela bebatuan (Mangesa dkk., 2016). Perbedaan habitat udang air tawar merupakan salah satu faktor 
terjadinya perbedaan karakter morfologi dari udang air tawar tersebut.

Udang air tawar dari famili Atyidae merupakan anggota Crustacea yang umum ditemukan di perairan tawar. Ciri utama dari famili Atyidae adalah tidak memiliki hepatic spine pada carapace serta kaki jalan (pereiopod) pertama dan kedua yang memiliki setae pada ujung chela (Wowor et al., 2004).

Famili Atyidae terdiri atas 469 spesies yang sebagian besar merupakan genus Caridina, genus ini memiliki 290 spesies ( De Grave and Fransen, 2011). Di Indonesia, khususnya di pulau Sulawesi dilaporkan sebanyak 54 spesies udang air tawar dari genus Caridina dengan 34 spesies diantaranya merupakan spesies endemik (De Man, 1892; Schenkel, 1902; Roux, 1904; Woltereck, 1937a, 1937b; Cai \& Ng, 2005; Zitzler \& Cai, 2006; Cai and Wowor, 2007; Klotz et al., 2007; von Rintelen et al., 2008; von Rintelen \& Cai, 2009; Cai \& Ng, 2009; Cai et al., 2009; Klotz \& von Rintelen, 2013; Annawaty \& Wowor, 2015)

Udang air tawar dapat hidup di hampir semua perairan tawar baik di perairan lentik (tergenang) maupun lotik (mengalir). Salah satu kawasan perairan di Sulawesi yang telah diketahui keanekaragaman udang air tawarnya adalah Danau Poso dan perairan sekitarnya.

Salah satu spesies udang air tawar penghuni Danau Poso adalah Caridina ensifera Schenkel, 1902. Spesies ini merupakan udang air tawar endemik yang diketahui hanya terdistribusi di Danau Poso (von Rintelen \& Cai, 2009). Caridina ensifera dicirikan oleh bentuk rostrumnya yang sangat panjang yang merupakan salah satu ciri khas dari udang air tawar penghuni perairan tenang atau berarus lambat.

Muara dari inlet sungai yang masuk ke Danau Poso memiliki kondisi habitat yang mirip dengan kondisi habitat di zona litoral danau, yaitu adanya tumbuhan di pinggir sungai yang akarnya menjuntai ke air, arus yang sangat lambat, dan substrat sungai yang terdiri dari pasir maupun pasir berbatu (observasi pribadi). Kondisi habitat yang seperti ini sangat memungkinkan untuk menjadi habitat bagi $C$. ensifera sebagaimana habitatnya yang ada di danau. Karena itu penelitian ini bertujuan untuk mengetahui distribusi dan preferensi habitat $C$. ensifera di dua inlet Danau Poso, yaitu Sungai Pomua Palandu dan Sungai Toinasa.

\section{Bahan dan Metode Waktu dan Tempat}

Penelitian dilaksanakan pada bulan Januari sampai April 2019 di sepanjang aliran Sungai Pomua Palandu dan Sungai Toinasa Kecamatan Pamona Barat, Kabupaten Poso, Sulawesi Tengah.

\section{Penentuan Stasiun Penelitian}

Penelitian ini dilakukan di sepanjang aliran Sungai Pomua Palandu dan sungai Toinasa. Penentuan stasiun didasarkan pada jarak aliran sungai dari muaranya di Danau Poso (Gambar 1).

\section{Pengambilan Sampel}

Pengambilan sampel dilakukan menggunakan metode purposive sampling yaitu dengan melihat habitat yang memungkinkan terdapatnya udang Caridina, seperti di sela-sela akar tumbuhan yang menjuntai ke air, di bawah atau di antara serasah dedaunan, di bawah kayu yang telah lapuk maupun di sela bebatuan. Sampel pada setiap stasiun dikoleksi dengan jumlah orang dan waktu yang telah ditentukan.

Sampel dikoleksi menggunakan alat tray net berukuran panjang $60 \mathrm{~cm}$, lebar $40 \mathrm{~cm}$, dan mesh size $2,6 \mathrm{~mm}$. Selanjutnya dicatat habitat dan jenis substrat tempat ditemukannya udang air tawar. Sampel yang diperoleh difiksasi dengan cara dimasukan ke dalam botol sampel yang telah berisi alkohol $96 \%$. Setelah itu diberi label yang meliputi lokasi penelitian, tanggal koleksi, habitat dan kolektor, selanjutnya jumlah individu dari setiap stasiun dicatat. Koordinat titik pengoleksian sampel dicatat menggunakan GPS (Global Positioning System). Kecepatan arus sungai dengan mengacu pada ketentuan menurut Welch and Lindell (1980) yaitu arus sangat lambat $(<0,10 \mathrm{~m} / \mathrm{s})$, lambat $(0,10-0,25$ $\mathrm{m} / \mathrm{s})$, sedang $(0,25-0,50 \mathrm{~m} / \mathrm{s})$, cepat $(0,50-1 \mathrm{~m} / \mathrm{s}$.

\section{Identifikasi Sampel}

Identifikasi sampel secara morfologi dilakukan di Laboratorium Biosistematika Hewan dan Evolusi menggunakan kunci identifikasi von Rintelen and Cai (2009). Penentuan karakter morfologi didapatkan dengan melakukan pengamatan terhadap sifat-sifat fenotip udang meliputi setae pada ujung chela, panjang rostrum, jumlah gigi rostral rostrum, panjang carapace, bentuk dan ukuran kaki jalan (pereiopod), jumlah claw pada ujung dactylus, bentuk pre-anal, ada atau tidaknya appendix interna pada pleopod (kaki renang) pertama dan perbandingan antara bagian-bagian dari udang tersebut.

\section{Hasil dan Pembahasan}

Caridina ensifera yang dikoleksi dari ke dua inlet Danau Poso ditemukan di bagian hilir sungai yaitu hilir dari masing-masing sungai yaitu hilir Sungai Pomua Palandu dengan koordinat 01ㄴ9'24,9" LS 12031'44,3" BT dan hilir Sungai Toinasa pada koordinat 01ํ⒌'55,6" LS 12032' 07,7" BT. Caridina ensifera yang ditemukan pada kedua hilir sungai berjumlah 32 individu yang 
terdiri dari 18 jantan dan 14 betina. 30 individu ditemukan di hilir Sungai Toinasa sedangkan sisanya sebanyak 2 individu ditemukan di hilir Sungai Pomua Palandu.

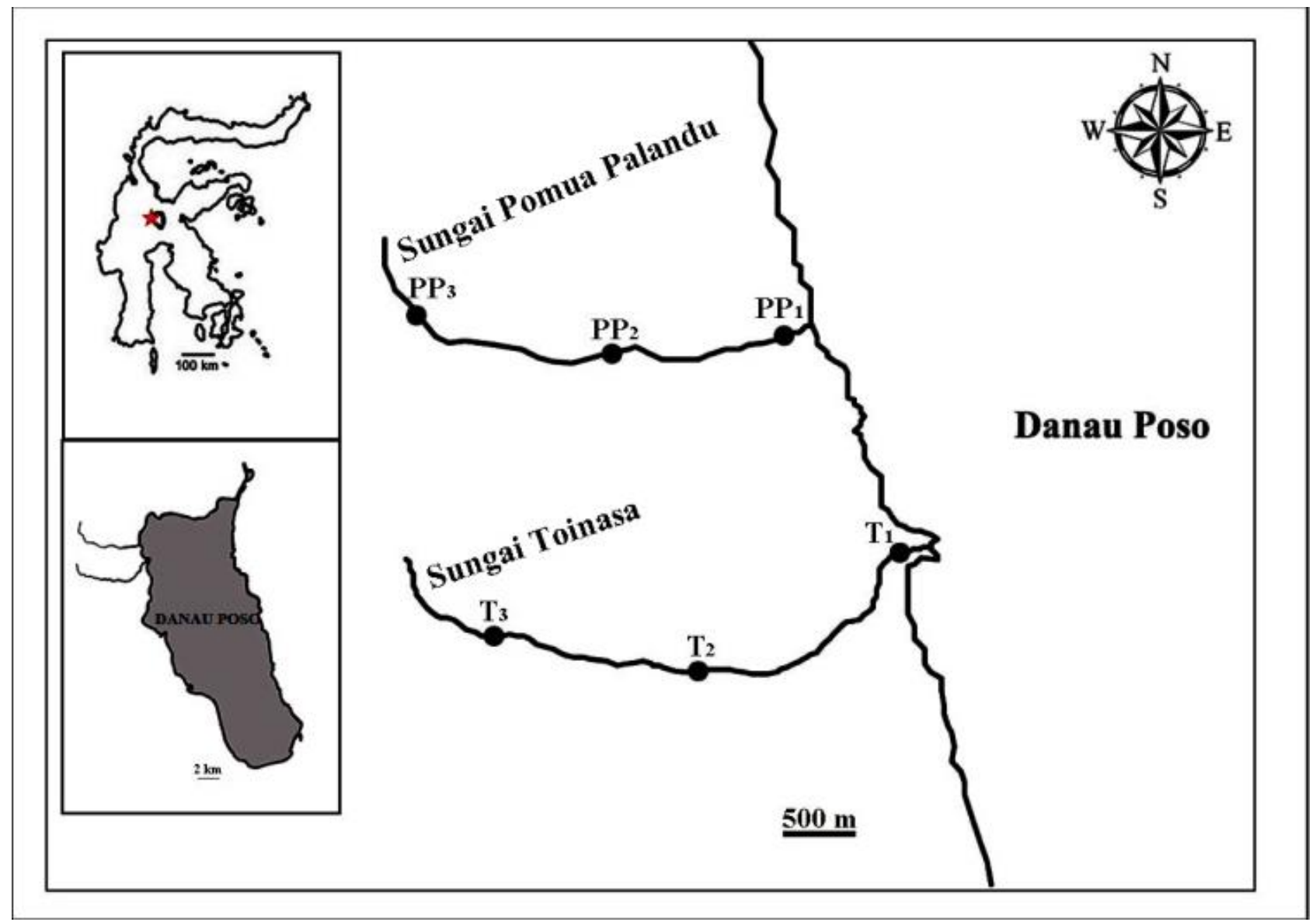

Gambar 1. Peta lokasi penelitian di Sungai Pomua Palandu dan Sungai Toinasa

\section{Diagnosis}

Caridina ensifera memiliki karakteristik morfologi berupa panjang carapace (CL) 3,32-5,3 mm ( $\mathrm{n}=32$ ). Rostrum sangat panjang hinggga melampaui ujung segmen ketiga antenullar peduncle. Jumlah gigi rostral pada bagian dorsal rostrum umumnya 9-15 ( $n=25)$, namun terdapat spesies dengan jumlah gigi rostral pada bagian dorsal rostrum 6-7 $(n=7)$. Jumlah gigi rostral di belakang mata $1-3(n=26)$. Jumlah gigi rostral di bagian ventral 16-29 ( $n=29)$, dan ditemukan 1 spesimen dengan jumlah 14 gigi. Carpus kaki jalan pertama berbentuk conical, Carpus kaki jalan kedua lebih panjang dari chela, memiliki pre-anal carina dan tidak memiliki projection pada telson (Gambar 2).

Morfologi dari $C$. ensifera yang ditemukan di kedua inlet Danau Poso memiliki kemiripan dengan morfologi spesies ini yang sebelumnya telah dilaporkan oleh von Rintelen and Cai (2009). Perbedaan keduanya dapat dilihat pada tabel 1.

\section{Preferensi Habitat Caridina ensifera}

Dalam penelitian ini ditemukan bahwa Caridina ensifera ternyata juga dapat menghuni perairan sungai namun dengan habitat yang tidak jauh berbeda dengan kondisi habitat danau. Habitat tempat ditemukannya $C$. ensifera di Sungai Pomua Palandu maupun Sungai Toinasa adalah di daerah hilir sungai dengan habitat di sela-sela akar tumbuhan yang ada di tepi sungai yang akarnya menjuntai ke dalam air (Gambar 3). Substrat berupa pasir atau pasir berbatu dengan kecepatan arus yang tergolong lambat. Karena itu ditemukannya C. ensifera di dua inlet sungai dari Danau Poso yang belum pernah dilaporkan sebelumnya ini tidaklah mengherankan. Mengingat habitat yang dihuni oleh $C$. ensifera yang berada di hilir sungai, memiliki kemiripan dengan salah satu habitat spesies ini di Danau Poso yang sebelumnya telah dilaporkan oleh von Rintelen and Cai (2009) yang menemukan C. ensifera di antara akar tanaman yang menjuntai ke air. 

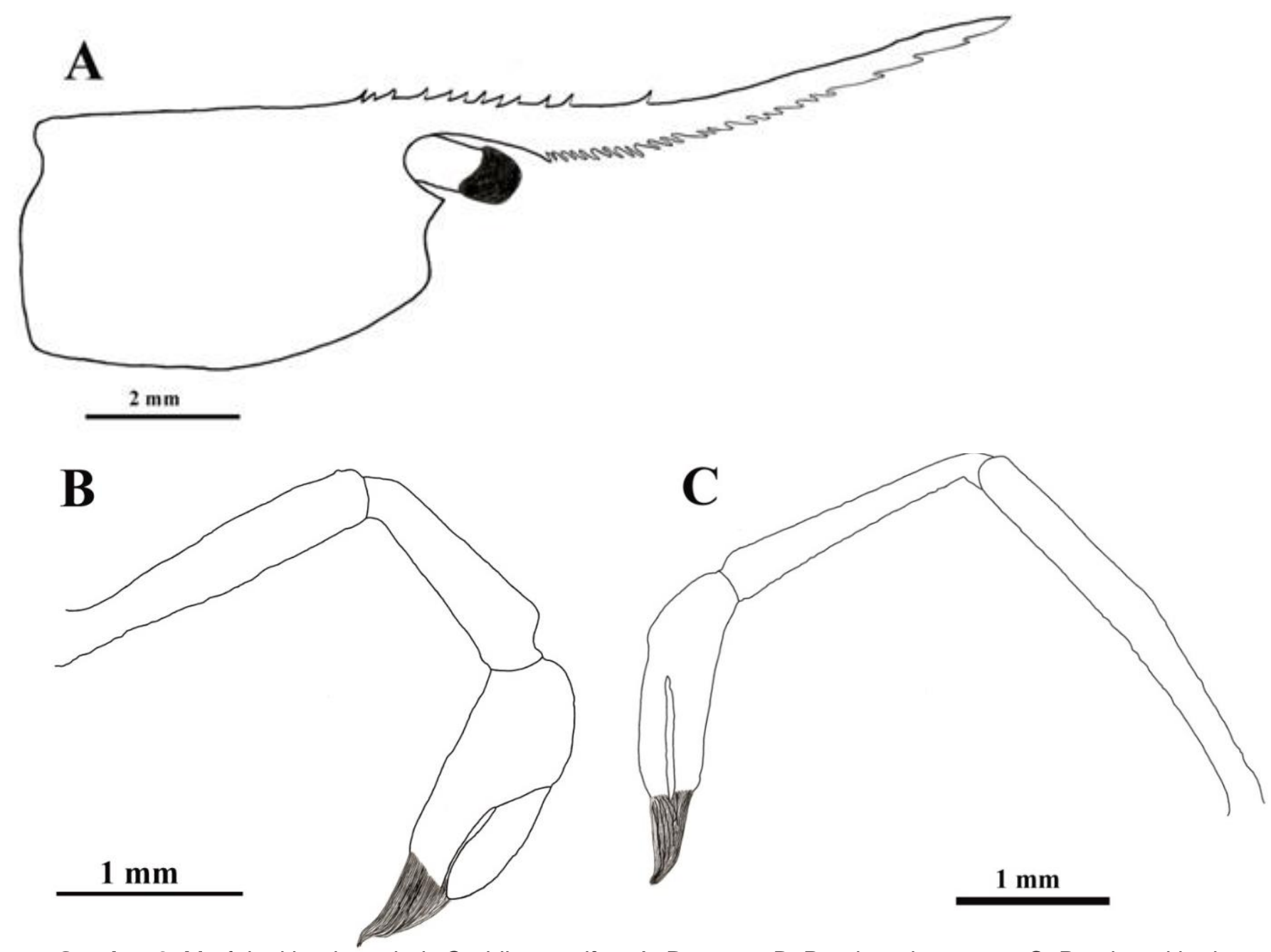

$1 \mathrm{~mm}$

Gambar 2. Morfologi bagian tubuh Caridina ensifera A. Rostrum; B. Pereiopod pertama; C. Pereiopod kedua

Habitat yang dihuni oleh $C$. ensifera yang ada di Danau Poso lebih bervariasi dibandingkan dengan habitat yang ditemukan di Sungai Pomua Palandu dan Sungai Toinasa. Preferensi habitat dari spesies yang paling melimpah di Danau Poso ini, menurut von Rintelen and Cai (2009) umumnya ditemukan berenang bebas atau kadang-kadang ditemukan juga di bebatuan, kayu atau permukaan pasir.

\section{Peta Distribusi}

Caridina ensifera diketahui sebagai spesies yang endemik di Danau Poso. Apabila dibandingkan dengan spesies-spesies Caridina lainnya yang ada di Danau Poso, spesies ini adalah udang Caridina yang paling melimpah di Danau Poso (von Rintelen and Cai, 2009). Peta distribusi Caridina ensifera di kedua inlet Danau Poso (Gambar 4), mengindikasikan bahwa udang ini hanya terdistribusi di bagian hilir sungai, namun tidak pernah ditemukan di bagian tengah ataupun bagian sungai yang lebih ke arah hulu. Hal ini terkait erat dengan kecepatan arus sungai yang lebih besar di bagian sungai yang lebih ke hulu sehingga habitat tersebut tidak sesuai dengan morfologi tubuh $C$. ensifera yang memiliki rostrum yang sangat panjang. Kondisi sungai berarus sedang hingga deras akan menyulitkan $C$. ensifera yang berostrum panjang dalam mempertahankan posisinya di sungai tersebut.

Distribusi C. ensifera di inlet Danau Poso merupakan catatan baru bagi spesies ini yang sebelumnya diketahui hanya terdistribusi di danau saja. Namun lokasi ditemukannya $C$. ensifera adalah di bagian hilir sungai yang kondisi habitatnya mirip dengan kondisi habitat dari $C$. ensifera yang sebelumnya dilaporkan dari Danau Poso. 
Tabel 1. Perbandingan morfologi Caridina ensifera di Danau Poso dan di inlet Danau Poso

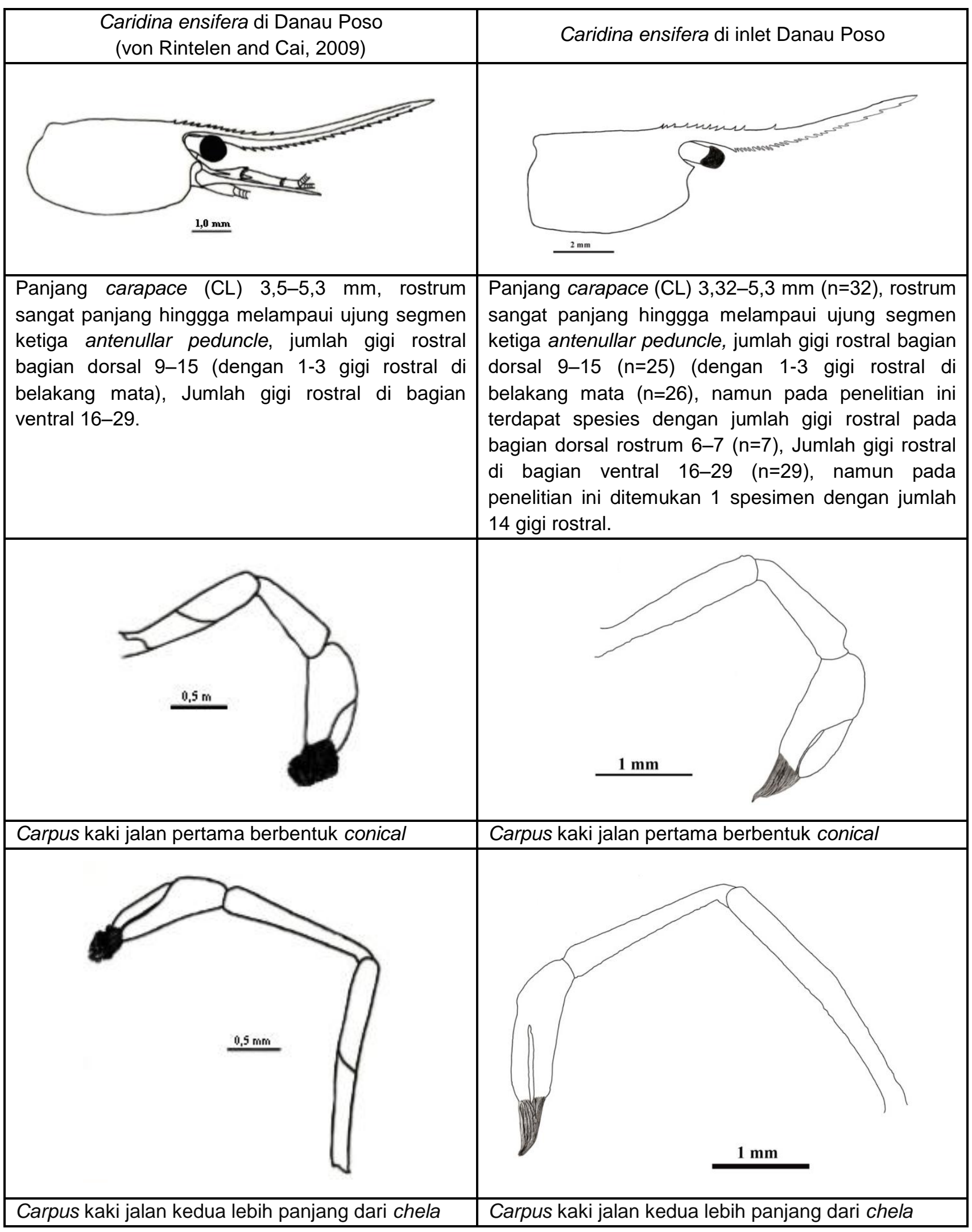




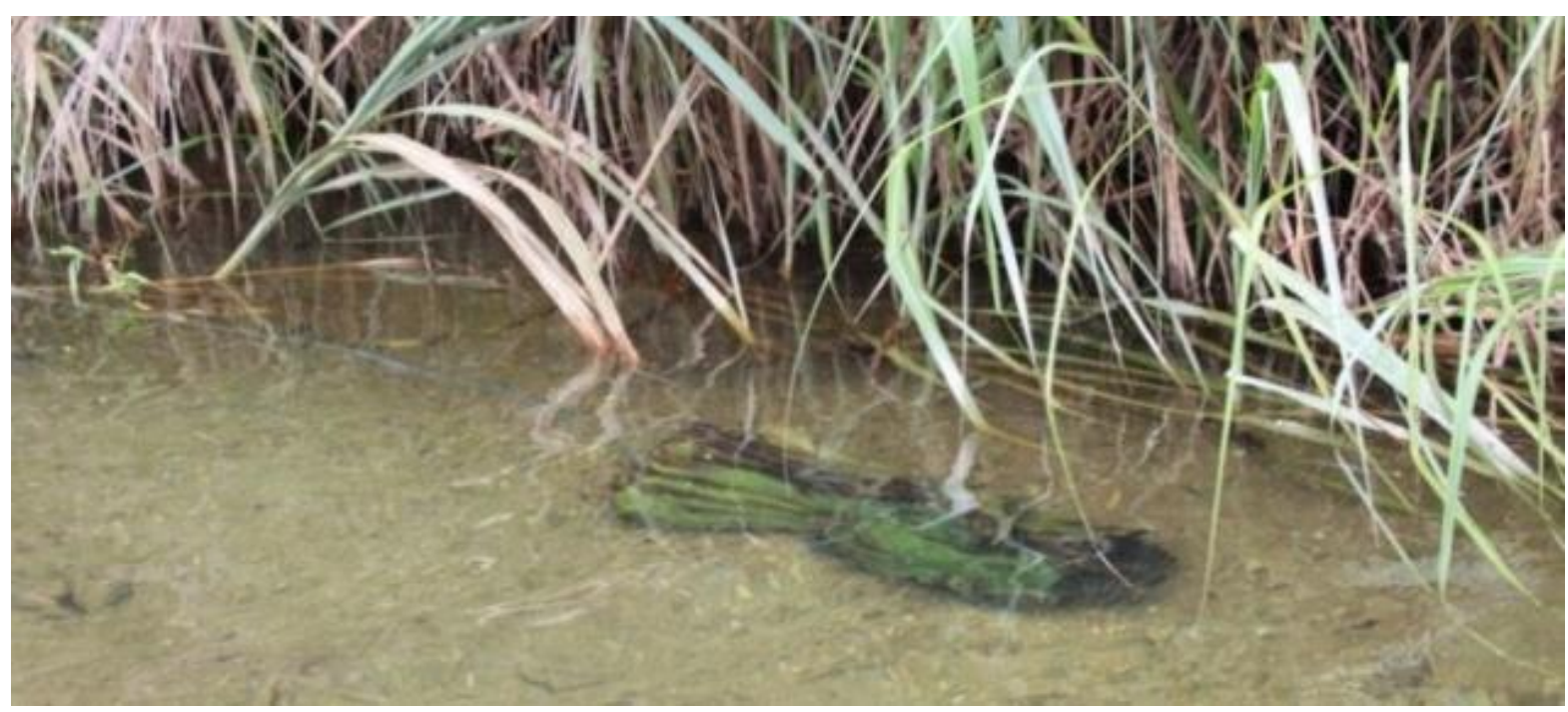

Gambar 3. Kondisi habitat di hilir Sungai Pomua Palandu

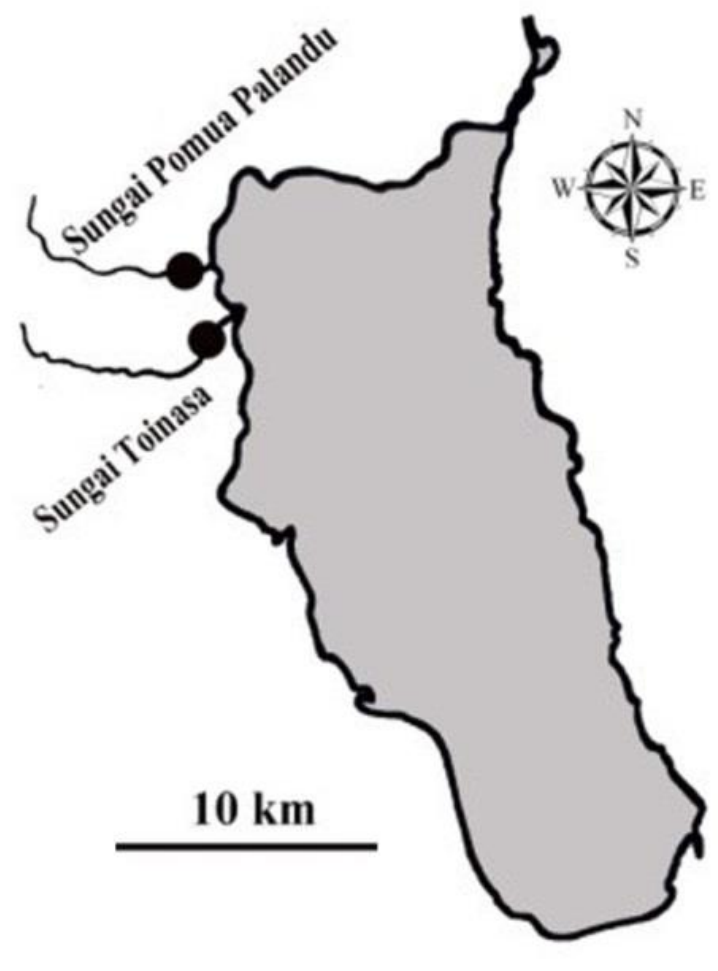

A

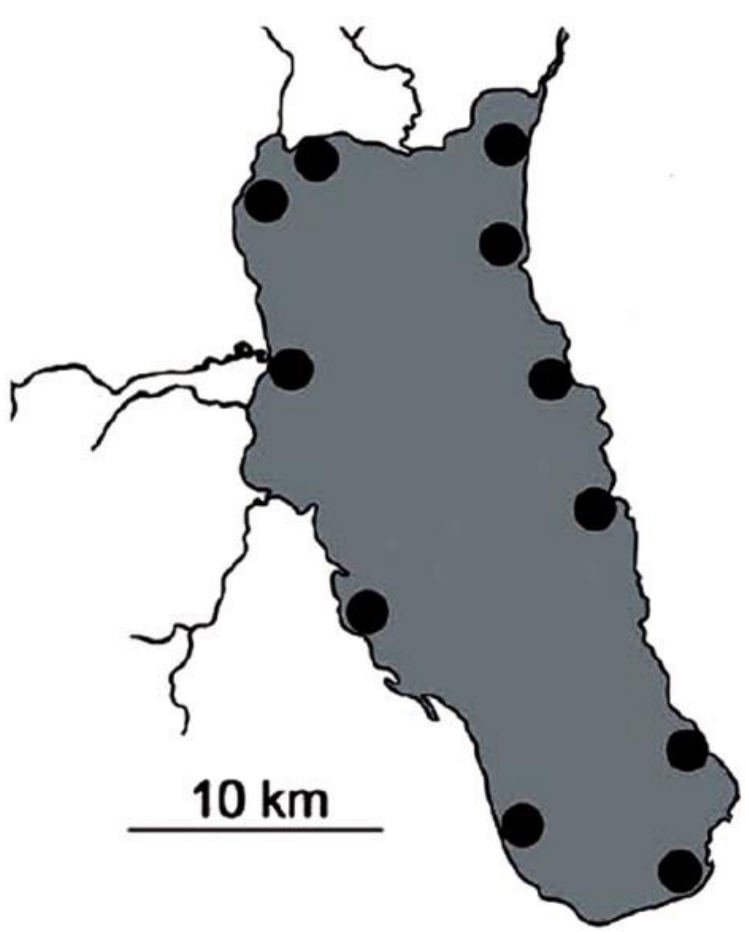

B

Gambar 4. Peta distribusi Caridina ensifera A. Pada studi ini B. Berdasarkan von Rintelen and Cai (2009)

\section{Ucapan Terima Kasih}

Terima kasih kepada Ibu Dr. Daisy Wowor dan Bapak Ujang Nurhaman yang telah membimbing penulis pertama dalam melakukan identifikasi udang air tawar pada saat melakukan magang di Laboratorium Crustacea, Museum Zoologi, Puslit Biologi LIPI.
Kepada Puji Rahayu, Aswandi, Rizki Ramadhana, Moh. Basit, Jason T. Karuntu, Preis Fransiska Malino, Evans Madiyono S.Si, Kurniawan Bandjolu S.Si dan Alfandi Gunawan Bando S.Si yang telah membantu penulis selama proses pengambilan sampel di Sungai Pomua Palandu dan Sungai Toinasa. Sebagian 
penelitian ini didanai oleh Anggaran Penelitian Hibah Penelitian Dasar pada tahun 2019 berdasarkan Surat Keputusan Nomor 351.v/UN28.2/PL/2019 dan Perjanjian Kontrak Nomor 100/SP2H/LT/DRPM/2019 yang diberikan kepada penulis kedua.

\section{Daftar Pustaka}

Annawaty, and Wowor, D., 2015, The atyid shrimp from Lake Lindu, Central Sulawesi, Indonesia with description of two new species (Crustacea: Decapoda: Caridea). Zootaxa, 3957(5): 501-519.

Cai, Y., and Ng, P. K. L., 2005, Marosina, a new genus of troglobitic shrimps (Decapoda, Atyidae) from Sulawesi, Indonesia, with descriptions of two new species. Crustaceana, 78(2):129-139.

Cai, Y., and Ng, P. K. L., 2009, The freshwater shrimps of the genera Caridina and Parisia from karst caves of Sulawesi Selatan, Indonesia, with descriptions of three new species (Crustacea: Decapoda: Caridea: Atyidae). J Nat Hist, 43(1718):1093-1114.

Cai, Y., Wowor, D., Choy, S., 2009, Partial revision of freshwater shrimps from Central Sulawesi, Indonesia, with descriptions of two new species (Crustacea: Decapoda: Atyidae). Zootaxa, 2045:15-32.

Cai, Y., and Wowor, D., 2007, Atyid Shrimps From Lake Poso, Central Sulawesi, Indonesia with Description of A New Species (Crustacea: Decapoda: Caridea). The Raffles Bulletin Of Zoology, 55(2): 311-320.

De Grave, S., and Fransen, C. H. J. M., 2011, Carideorum catalogus: the recent species of the dendrobranchiate, stenopodidean, procarididean and caridean shrimps (Crustacea: Decapoda), Zool. Med. Leiden, 85(9): 195-589.

De Man, J. G., 1892, Decapoden des Indischen archipels. In: Weber $\mathrm{M}$, editor. Zoologische ergebnisse einer reise in Niederländisch OstIndien: zweiter teil. 2:265-527. Bremen: Dogma. Plate 15- 29.

Klotz W, Karge A, von Rintelen K. 2007. A redescription of two atyid shrimps (Decapoda: Caridina) from Central Sulawesi, Indonesia. Zootaxa, 1466:1-10

Mangesa, H. E., Fahri, dan Annawaty., 2016, Inventarisasi Udang Air Tawar di Sungai Toranda, Palolo, Sigi, Sulawesi Tengah, Indonesia. Natural Science, 5(3): 288-295.
Roux, J., 1904, Décapodes d'eau douce de Célèbes (Genres Caridina \& Potamon). Revue Suisse de Zoologie, 12: 539-572.

Schenkel E. 1902. Beitrag zur kenntnis der Dekapodenfauna von Celebes. Verhandlungender Naturforschenden Gesellschaft in Basel, 13: 485-585.

von Rintelen, K., and Cai, Y., 2009, Radiation of Endemic Species Flocks in Anciant Lakes: Systematic Revision of the Freshwater Shrimp Caridina H. Milne Edwards, 1837 (Crustacea: Decapoda: Atyidae) from the Ancient Lakes of Sulawesi, Indonesia, with the Description of Eight New Species. The Raffles Bulletin of Zoology, 57(2): 343-452.

von Rintelen, K., Karge, A., Klotz, W., 2008, News from a small islandfirst record of freshwater shrimp (Decapoda, Atyidae, Caridina) from Peleng, Banggai Islands, Indonesia. J Nat Hist, 42(3334): 2243-2256.

Welch, E. B., and Lindell, T., 1980, Ecological Effects of Waste Water. Cambridge University Press.

Woltereck, E., 1937a, Systematischvariationsanalytische untersuchungen über die rassen- und artbildung bei süßwassergarnelen aus der gattung Caridina (Decapoda, Atyidae). Int Rev ges Hydrobiol Hydrogr, 34(1-6): 208-262.

Woltereck, E., 1937b, Zur Systematik und geographischen verbreitung der Caridinen. Int Rev ges Hydrobiol Hydrogr, 34(1-6): 294-330.

Wowor D., Cai Y., Peter K. L., 2004, Crustacea: Decapoda, Caridea. In: Yule CM, Yong HS (eds.). Freshwater Invertebrates of the Malaysian Region. Malaysia: Monash University Malaysia.

Wowor, D., Muhtu, V., Meier, R., Balke, M., Cai, Y., and Ng, P. K. L., 2009, Evolution of life history traits in Asian freshwater prawns of the genus Macrobrachium (Crustacea; Decapoda; Palaemonidae) based on multilocus. molecular phylogenetic analysis. Molecular Phylogenetics and Evolution, 52(2): 340-350.

Zitzler, K., and Cai, Y., 2006, Caridina spongicola, new species, a freshwater shrimp (Crustacea: Decapoda: Atyidae) from the ancient Malili lake system of Sulawesi, Indonesia. Raffles Bull Zool, 54(2): 271-276. 